\title{
Salt-seeking behaviour of mammals and ants in a low-sodium Australian alpine environment
}

\author{
Rachael Robb, Bronte Sinclair, Islay Andrew, Kristi Lee, \\ Xiaoyun Li, Isabella Robinson, Holly Sargent, Giles Young
}

\section{Abstract}

Salt is an essential nutrient that is found in low concentrations in alpine areas. Salt is thought to be sought by animals through a variety of behaviours including chewing wood, using salt licks, digging and eating plants with high sodium concentrations. We conducted three experiments to investigate whether animals in a low-sodium Australian alpine environment would show a preference for sodium chloride over other salts. Our experiments tested whether 1) alpine mammals would chew on sodium chloride-soaked wooden stakes, 2) ants would be attracted to salt grains and 3) the sodium concentrations in alpine plants are lower compared to plants in other Australian environments. We found that herbivorous mammals, such as rabbits, chewed a greater number of wooden stakes treated with sodium chloride than those treated with other salt solutions. No significant preference was recorded by ants for salt or sugar. Lastly, we found sodium concentration of vegetation decreases with increasing elevations, but the relationship was not statistically significant. Our study was conducted at three locations at elevations of $920 \mathrm{~m}, 1,200 \mathrm{~m}$, and 1,860 m within Kosciuszko National Park in the Snowy Mountains, New South Wales, Australia.

\section{Introduction}

The Snowy Mountains area is reported to have low-sodium soil and vegetation mainly due to nutrient leaching by annual snow melt, moderate precipitation, freezing and thawing (Best et al. 2013). This results from sodium ions in the soil dissolving in water, causing downhill run-off to leach the nutrients from higher elevation soil (Blair-West et al. 1968). 
Additionally, the area's low sodium concentration is a result of the lower sodium concentration of rainfall further from the coast (Kaspari et al. 2010). This potentially causes higher elevations to have lower sodium concentrations than at lower elevations. The alpine species in the high elevation regions are suited to their environment with characteristics to cope with the environmental restrictions and conditions of the ecosystem, including the low availability of sodium (Belovsky and Jordan 1981). For example, kangaroos were found to regulate their mineral homeostasis with licks, and in the Snowy Mountains showed physiological adaptations for sodium conservation compared to the Victorian coast (Best et al. 2013). Nutrient cycling in plants is also an example of an ecosystem function that can respond to limited nutrient availability and is thought to be affected by climate change (Díaz and Cabido 1997).

An appetite for salt has been observed globally through selective grazing by sheep, and snow shoe hares gnawing salt-exposed wood (Blair-West et al. 1968). Additionally, salt licks are known to be sought by ruminants, gorillas, butterflies and bees (Kaspari et al. 2008). Supporting studies have suggested that animals seek sodium from vegetation matter when the surrounding soils have been leached of sodium (Belovsky and Jordan 1981), such as mountain gorillas eating decaying wood for 95 per cent of their sodium intake (Rothman et al. 2006). It is not known whether the animal behavioural response to seek salt comes from a need to supplement their diet, a taste for sodium, the low sodium concentration in their environment compared to other environments, or a combination of these interactions (Denton 1982; Belovsky and Jordan 1981; Weir 1972).

Rothman et al. (2006) observed that herbivores with sodium-deficient diets licked or chewed items with high sodium concentrations. Australian herbivores are known to seek high-sodium food while excreting limited sodium (Belovsky and Jordan 1981). Using these observations, wooden stakes soaked in salt solutions have been used to test herbivorous mammals for sodium-seeking behavioural responses (Blair-West et al. 1968). Furthermore, using tubes of sodium solution for baits, ant communities have provided an invertebrate test species and a model system for the biogeographical variation of salt availability (Kaspari et al. 2008; Kaspari et al. 2010). The sodium concentration of vegetation within different environments has been measured in previous studies such as by Denton (1982), who recorded a range of sodium concentrations from $2.25 \mathrm{mmol} / \mathrm{kg}$ to $168.75 \mathrm{mmol} / \mathrm{kg}$, with the Snowy Mountains having the lowest sodium concentration. Denton's study was conducted to provide context and determine a reason for animals seeking to increase their sodium intake. 
Our study aims to determine the behavioural response of animals to sodium concentration, focusing on the active behaviour of alpine ants and mammals like rabbits and wallabies to sodium and other salts. We also tested the sodium concentration of the surrounding vegetation to determine if and why alpine animals at different elevations actively seek and consume salt in their diet.

The significance of this study is in its application for resource management and conservation (Weir 1972) through revegetation, the control of invasive species like rabbits (Blair-West et al. 1968), and minimising the negative effects of road salting such as the suppression of vegetation growth and germination and increased consumer activity (Kaspari et al. 2010). It will contribute to the knowledge about the Kosciuszko National Park and its inhabitants, and the data collected could be applied to climate change scenarios when considering how animals may respond to temperature increases and shifting seasonal conditions in the low-sodium environment (Díaz and Cabido 1997). It may also have potential connections to studies in other alpine areas where animals may show similar or different behavioural responses to sodium.

We hypothesise that alpine animals will actively seek salt and prefer sodium to other salts. Herbivorous alpine mammals are expected to have greater preference for sodium chloride-soaked wooden stakes rather than stakes treated with other salt solutions, when compared to water-treated stakes. We also hypothesise that invertebrates, such as ants, will show a preference for sodium chloride when compared to white sugar. Lastly, we hypothesise that sodium concentration will decrease with increasing elevation, and alpine plants will be lower in sodium compared to other Australian plants.

\section{Methods}

\section{Sites}

The experiments were conducted in December 2015 across three sites along an elevation gradient: Waste Point $(920 \mathrm{~m})$, Sawpit Creek $(1,200 \mathrm{~m})$ and Charlotte Pass $(1,860 \mathrm{~m})$. The experiments at Waste Point were conducted near human residences with a lake in the area. Sawpit Creek is a picnic spot near a slope susceptible to road run-off. Charlotte Pass is located in the alpine zone, and the experiments were conducted in a human-occupied resort area near walking paths. 


\section{Stakes}

Sixty wooden stakes were soaked in salt solutions of either sodium chloride $(\mathrm{NaCl})$, potassium chloride $(\mathrm{KCl})$, magnesium chloride $(\mathrm{MgCl})$, sodium bicarbonate $\left(\mathrm{NaHCO}_{3}\right)$, or distilled water $\left(\mathrm{H}_{2} \mathrm{O}\right)$ as a control. One of each treatment formed a five-stake plot, and four plots were set up in each of the three sites: Waste Point, Sawpit Creek and Charlotte Pass. The plots were positioned in areas of likely herbivorous mammal activity, where mostly rabbits and wallabies had previously been observed. Thirty of the 60 salt-treated wooden stakes were placed in the field unmonitored for three weeks, the remaining 30 for two days. Each stake was hammered into the ground for a quarter of its length, to leave a similar surface area exposed. After the test duration elapsed, each site was visited and the stakes in each plot observed for signs of chewing. The chew intensity of salt-soaked wooden stakes was measured using a categorical rating from 1 to 4 indicating none, light, moderate and heavy chewing.

\section{Ants}

In the same three sites as the wooden stakes, four Eppendorf tubes were placed around each ant nest, with two active nests per location; two tubes containing $0.25 \mathrm{ml}$ of iodised table salt grains, two containing $0.25 \mathrm{ml}$ of white sugar grains. The tubes were arranged in a random order in a semicircle around the chosen nest, and if needed staked into position with thin wooden skewers. The Eppendorf tubes were left open for 45 minutes then checked for ants inside, which were counted and removed, and then the tube sealed. Before and after placement, the mass ( $\mathrm{g}$ ) of the tube and treatment was measured and the difference calculated. The same procedure was used for 14 control tubes: 10 empty tubes placed at an active nest at the Charlotte Pass site for 45 minutes, and four tubes of salt or sugar with two replicates each placed in an ant-free area within the Charlotte Pass ski lodge. The difference in mass of the Eppendorf tube and treatment of salt or sugar grains by ants was corrected using the measured average mass differences of the control tubes, to allow for the changes in mass unrelated to the ants, such as through added moisture. The correcting difference was subtracted from each tube's original change in mass. 


\section{Vegetation}

Following the methods used by Denton (1982), we collected foliage samples from each of one dominant grass (Poa sp., unidentified), shrub (Hovea montana, Prostanthera cuneata, Cassinia sp., Cheysocephalum sp., Leptorhynchos sp.), and tree (Eucalyptus pauciflora) to provide a mixed representation of alpine vegetation. Enough leaves to constitute a $0.5 \mathrm{~g}$ sample of each vegetation type were collected from each of the three sites and placed in labelled paper bags $(\mathrm{n}=9)$. The leaves were then dried using a small oven set at $70^{\circ} \mathrm{C}$ for approximately 12 hours overnight, until the moisture in the leaves was completely removed. We prepared $0.5 \mathrm{~g}$ of each foliage sample using a coffee grinder in combination with a mortar and pestle to form a fine powder, and added the sample to a Falcon tube labelled with the plant's scientific name and its collection site. To each of the Falcon tubes, we added $30 \mathrm{~mL}$ of distilled water and the tube was shaken vigorously for 30 seconds. Once settled, we removed $30 \mathrm{~mL}$ of the extract using a syringe then filtered it into a new Falcon tube with $11 \mathrm{~cm}$ filter paper. To get a $\mathrm{mmol} / \mathrm{kg}$ measurement of the sodium ions in each vegetation sample, we added $3 \mathrm{~mL}$ of ionic strength adjuster for $30 \mathrm{~mL}$ of extract and then measured using an HI98191 ISE meter with a FC300B Combination Sodium Electrode (Hanna Instruments).

\section{Statistical analysis}

To analyse the results of the chewing intensity (categorical rating 1 to 4 ), removal of salt and sugar (g) and vegetation sodium concentration $(\mathrm{mmol} / \mathrm{kg})$, no formal statistical tests were performed because the samples sizes were very small. However, we did calculate the mean, standard deviation and error, confidence interval, degrees of freedom and t-interval of each variable.

\section{Results}

At three different sites at different elevations, we tested the intensity of chewing of the wooden stakes, the removal of salt grains by ants and the sodium concentration of leaves. At each of these sites, the salt-treated stakes showed some degree of chewing, ants showed behavioural interest in the salt and sugar grains, and low concentration of sodium was measured in the surrounding foliage. 
In the experiment to test herbivorous mammals for salt preference behaviour, wooden stakes soaked with salt solutions showed physical signs of chewing when compared to the control stakes treated with water. The stacked column graph showed that the highest number of stakes chewed were treated with $\mathrm{NaCl}$, which we also observed had the heaviest chewing (Figure 1).

As some of the stakes were in position at the study sites for three weeks and others for two days, we analysed the results separately. The stakes in position for two days did not show visible chewing, which implies that a longer time period may be required for animals to show a behavioural response to sodium. Therefore, we discarded the two-day sample, reducing the sample size to 30 but increasing the precision and accuracy because the stakes included were those that could show a result. We found that 23 of the stakes in position for three weeks appeared untouched. No stakes treated with the control of water were chewed and of the seven stakes that showed signs of chewing, there were three $\mathrm{NaCl}$ stakes, two $\mathrm{MgCl}$ stakes, one $\mathrm{NaHCO}_{3}$ stake and one $\mathrm{KCl}$ stake.

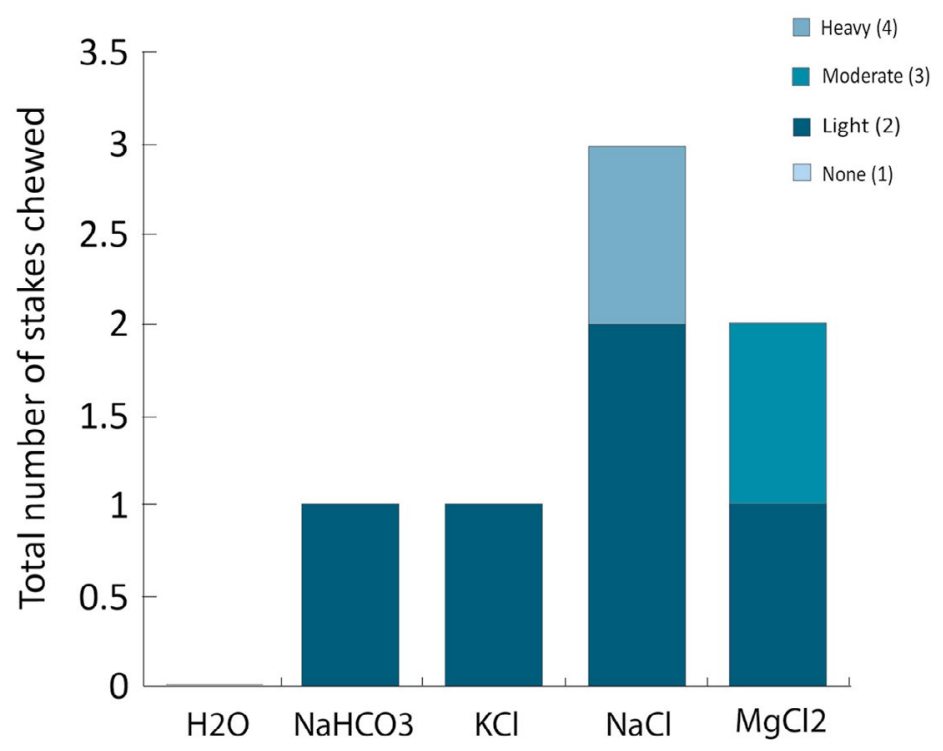

Figure 1: Herbivorous alpine mammals appear to seek $\mathrm{NaCl}$ over other treatments. The total number of stakes chewed for each treatment of water $\left(\mathrm{H}_{2} \mathrm{O}\right)$, sodium bicarbonate $\left(\mathrm{NaHCO}_{3}\right)$, potassium chloride $(\mathrm{KCl})$, sodium chloride $(\mathrm{NaCl})$ and magnesium chloride $(\mathrm{MgCl})$ was separated into their rating category, with each colour denoting the intensity of chewing.

Source: Authors' data. 


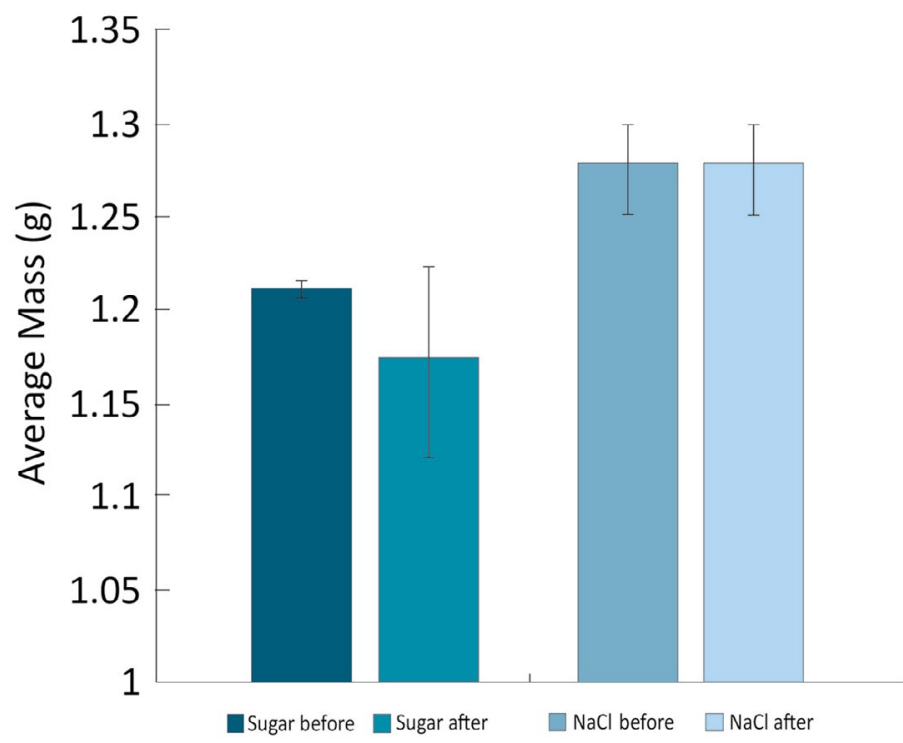

Figure 2: The average mass of the Eppendorf tubes containing table salt $(\mathrm{NaCl})$ or sugar grains before and after placement at the entrance to an active ant nest. Ants did not significantly seek salt or sugar.

Note: Confidence intervals are represented by error bars.

Source: Authors' data.

To see if only mammals showed a preference for salt we tested another animal, using ants as an invertebrate specimen. The average mass of both sugar and salt before and after exposure to ants was not significantly different (Figure 2). Despite this, our observations suggested a preference for sugar when one Eppendorf tube of sugar was completely emptied within the test duration.

At each site, we tested the leaf sodium concentrations of mixed species $(n=3,4)$ to provide context to the potential reasons why alpine animals might be seeking to increase sodium in their diet. The resulting trend suggests that plants at higher elevations have lower sodium concentration (Figure 3). The error bars show the confidence intervals, indicating no significant difference between the sodium concentrations of the vegetation at the three elevations, despite the observable decreasing trend.

The data taken around Charlotte Pass within the Snowy Mountains was consistent with the data from a previous study by Denton (1982). These areas were shown to have vegetation containing the lowest sodium concentration compared to other areas of Australia (Figure 4). 


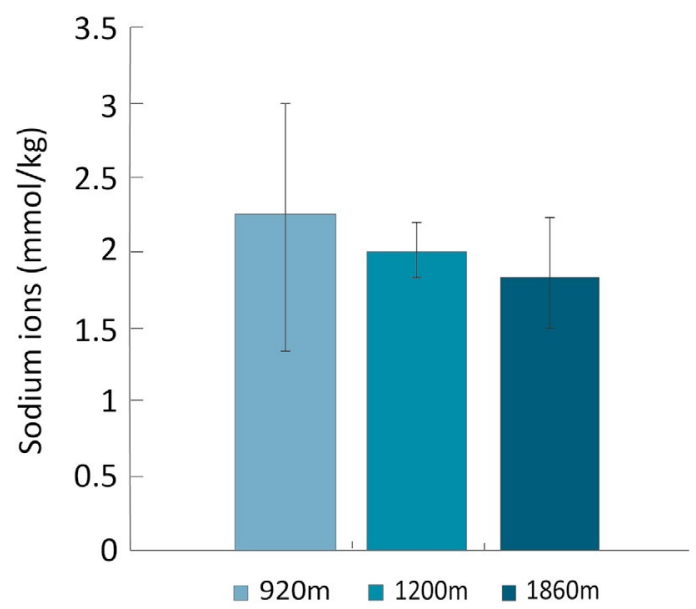

Figure 3: The average sodium ion content measured in a mixed selection of vegetation from Waste Point $(920 \mathrm{~m})$, Sawpit Creek $(1,200 \mathrm{~m})$, and Charlotte Pass $(1,860 \mathrm{~m})$ is shown with error bars displaying the confidence interval. Trend suggests that plants at higher elevations have lower $\mathrm{Na}+$ concentration.

Source: Authors' data.

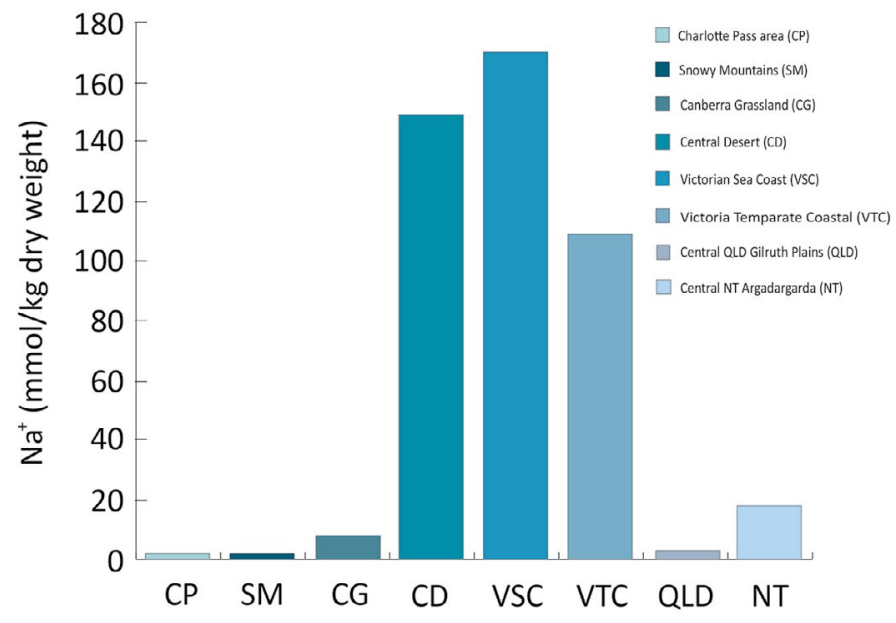

Figure 4: Sodium concentration in Charlotte Pass and the Snowy Mountains is lower than in other Australian regions. The sodium concentration ( $\mathrm{Na}+$ ) data collected in our study of the Charlotte Pass area was compared to the data of a previous study by Denton (1982), which measured the average sodium concentrations in the Snowy Mountains, Canberra Grassland, Central Desert, Victorian Sea Coast, Victoria Temperate Coastal, Central Qld Gilruth Plains, and the Central NT Argadargarda.

Source: Denton (1982) and authors' data. 


\section{Discussion}

The results showed some preference for sodium by alpine animals and a possible connection to the low-sodium environment; however, this was mostly through trends rather than by statistically significant results. The stakes experiment supported our first hypothesis, but the results from the ant and vegetation experiments could neither confirm nor refute their respective hypotheses.

In the first experiment, the sodium chloride-soaked stakes had the highest number of stakes chewed (3) at the highest intensity of chewing (4) compared to the other salt treatments. This suggests herbivorous mammals in the alpine region have a preference for sodium chloride. Previous observations by Best et al. (2013) similarly recorded a preference for sodium licks over potassium, magnesium or water. Blair-West et al. (1968) also suggested rabbits mostly chewed $\mathrm{NaCl}$ stakes over other salt solutions in spring and early summer, the season our study was completed. The highest chewing intensity was at our highest elevation site, coinciding with the theory that higher-elevation alpine environments have lower salt concentrations. This was supported by the third experiment's vegetation having the same range of sodium content to those recorded by Denton (1982), whose measure of Australian plants within the alpine region were much lower than other Australian plants. Other minerals and salts like calcium, potassium and magnesium are possibly attractive to animals as they are also present in the salt licks, soil and vegetation around which animals such as kangaroos and elephants are observed to demonstrate sodium-seeking behavioural responses (Best et al. 2013; Weir 1972).

Sodium can cause other changes in behaviour such as digging, which we observed at Waste Point around the base of the $\mathrm{NaCl}$ and to a lesser extent the $\mathrm{NaHCO}_{3}$ stakes, which we suspect was the work of wallabies and rabbits. Digging for sodium is behaviour observed in rabbits, as well as elephants and gorillas (Blair-West et al. 1968; Weir 1972; Rothman et al. 2006). Licking has been another commonly reported behavioural response (Best et al. 2013; Blair-West et al. 1968), but without camera monitoring we could not confirm licking behaviour. Unexpectedly, when we collected the wooden stakes at the end of the two-day duration, we observed a ladybug and a cocoon on the $\mathrm{NaCl}$ stake. The observation could not be confirmed as an unconnected occurrence or as one related to the sodium-treated stake. 
The stakes treated with magnesium chloride had the second highest number of stakes chewed (2). Blair-West et al. (1968) also found that wild rabbits chewed wooden pegs treated with magnesium, potentially due to magnesium depletion in the rabbits' tissue from sustained high blood aldosterone during summer. The same study observed behavioural interest of rabbits in $\mathrm{NaCl}$ and $\mathrm{NaHCO}_{3}$ stakes in spring and early summer, and some chewing of the $\mathrm{KCl}$ stakes, which coincides with the light chewing of one $\mathrm{KCl}$ stake we observed (Blair-West et al. 1968).

In the ants experiment, a significant change in mass would potentially indicate ants sought to remove salt or sugar from their respective Eppendorf tubes. However, as there was no significant change in average mass, seen by the overlapping confidence intervals, it cannot be confirmed that ants seek salt or sugar. Studies by Kaspari et al. (2008) suggested different ant behaviour than we found in our study; in Kaspari's studied grassland, salt solutions were preferred over sugar by $10-20$ per cent of bait usage, and sugar was preferred in coastal areas while further inland the preference was for sodium chloride. These trends contrast with the lack of statistically significant interest we observed ants showing to salt or sugar grains.

The small, black ants tested in our study were thought to be herbivorous, but nothing was known with certainty. As our studied ant species was not identified, the diet and lifestyle of the ants may have been the reason for the different observations. This leads to the style of diet-whether herbivorous or carnivorous-being an alternative but not entirely conflicting theory about why any animal would seek salt, other than a low-sodium environment. Diet is thought to influence sodium bait usage, with herbivores having higher usage than carnivores (Kaspari et al. 2008). This may be due to carnivores being less prone to sodium deficiency because they eat herbivores, which have high tissue sodium content (BlairWest et al. 1968). The concept is not completely conflicting because the diet of herbivores, omnivores and carnivores interact and rely on the availability of nutrients in the environment.

Another possible explanation for conflicting thoughts would be that the mode of presentation of sodium to both the ants and herbivorous mammals may have influenced the results of the experiments. We recommend further investigation into the alternatives to chewing wood and presentation of solid grains, such as isotonic solutions or foodstuff with a high sodium concentration (Blair-West et al. 1968). 
The sodium concentrations of alpine plants in our study and Denton's were much lower than published values of other Australian plants, which were as high as $168.8 \mathrm{mmol} / \mathrm{kg}$ dry weight on the Victorian coast, but close to the $2.7 \mathrm{mmol} / \mathrm{kg}$ average recorded in the central Queensland Gilruth Plains (Denton 1982). The salt content of the plants from the Snowy Mountains given in Denton's study range from 0.1 to $3.8 \mathrm{mmol} / \mathrm{kg}$ dry weight, with an average of $2.25 \mathrm{mmol} / \mathrm{kg}$. The sodium values we measured, an average of $2.04 \mathrm{mmol} / \mathrm{kg}$, were within this range.

Human activity has influenced sodium supply and animal distribution (Jensen et al. 2014; Kaspari et al. 2008). Road salting increases the natural salt levels in the environment and chloride levels increase the $\mathrm{pH}$ of the soil, exacerbating the already acidic soils at high elevations (Jensen et al. 2014). The increase in salt in places where road run-off is high can harm native vegetation growth and nutrient uptake, suppressing seed germination as well as polluting local waterways with chloride ions (Kaspari et al. 2010). Higher salt concentration along roads would also promote consumers (Kaspari et al. 2010), potentially increasing the risk of roadkill by drawing animals closer to the road in the search for food with higher sodium content. Invasive animals would be influenced by road salting; through scat observations, we thought rabbits were the animal most commonly chewing on the stakes. Increasing the salt concentration through salting could influence rabbit population density and distribution, potentially leading to concentrated damage to soil quality and native vegetation communities as herbivory is increased (Forsyth et al. 2015; Kaspari et al. 2010). A similar occurrence was reported in African elephants, whose distribution and increase in population density was concentrated where the water and soil have high sodium content (Weir 1972).

\section{Errors and improvements}

The method of rating the chew intensity of each stake into categories was susceptible to bias and inaccuracy, leading to random errors. This could be minimised by using a numerical method of measuring the chewing, such as scanning the surface area or weighing each stake before and after the sample duration (Blair-West et al. 1968). This would be further improved and supported by introducing camera monitoring for each plot, such as used in the study conducted by Best et al. (2013), to more accurately observe and record which animals chewed the stakes. This information would allow more accurate categorisation of the activity at each stake, 
including the duration of visit, how many animals visited and identifying other indications of the animal salt-seeking activity, such as licking and digging. Monitoring would help address the unknowns in our study, such as which animals were responsible for the marks on the stakes and the digging found at the base of some stakes. The type of wood used for the stakes could also be better controlled if further investigation was done; perhaps consistently using softer wood to better show chew marks (Blair-West et al. 1968).

The method of testing for sodium or sugar preference using the average mass differences was flawed. This was because the difference caused by the removal of one or two grains was not significant, the method of presentation and concentration of salt possibly did not fit with an ant's natural diet, and the mass would be unbalanced by interfering factors like moisture or dirt collecting inside the tubes. Therefore it is likely that the results would not show a preference if there was only a slight difference between the initial and end mass. It also did not allow for behaviour like the ants emptying a tube containing the sugar treatment to contribute significantly to the data. The time factor of 45 minutes limited the ant experiment as the ants may not have been continuously active; natural diet could dictate the $0.25 \mathrm{~mL}$ of salt would not be needed at once, and so they removed the small amount that satisfied their requirement and then left. We also observed that there was less activity at collection than when the tubes were set up. Considering these factors, if tested over a period of days or weeks, it would be likely that more salt and sugar would be removed overall as the ants may return to the known nutrient sources.

Increasing the replicates would improve all three experiments; through increasing the duration of each experiment, having an elevation gradient with more than three sites and a larger variety of study animals, the results would more likely be statistically significant. Additionally, we could increase the number of stake plots and nest samples, collect a greater range of vegetation samples, as well as test the soil and other plant components for sodium.

Another contribution to further study would be to run the ant experiment with other known species of ants to see their reaction to the salt and sugar treatments. This would allow us to collect more information, including what the ants' natural diet included or lacked (Kaspari et al. 2008). 


\section{Applications}

Our study of alpine animals' responses to sodium in the environment has applications to the management of revegetation, as the choice of flora for alpine environment restoration would need to possess the physiological and functional traits that contribute towards resilience to low-sodium soil. The flora would also be required to survive the other environmental and climate conditions of the region such as seasonal availability of nutrients, snow duration and tolerance to temperature extremes, soil chemistry and moisture availability (Blair-West et al. 1968; McGill et al. 2006).

\section{Significance}

The combination of stakes, ants and vegetation testing related to animal behavioural responses to sodium has not been previously completed in the elevation gradient from Waste Point to Charlotte Pass. Therefore, our study provides new information about the area and data that can be compared to existing studies of similar or different environments. This contributes towards a greater understanding of the patterns of sodium distribution and animal response and its application in practical management and conservation.

The low sodium concentration we measured in the vegetation does suggest that animals seek sodium because of a deficiency in their environment. However, for a definite conclusion of whether alpine animals seek salt, and for what reason, more research would have to be done into other animals' behaviour and diets (Blair-West et al. 1968). Further clarification would also be needed of the low sodium concentration in the alpine environment compared to other ecological, climatic and seasonal conditions that could influence animals seeking salt (Weir 1972).

Knowledge of salt and nutrient availability in the alpine environment has management and conservation applications. Therefore, as our study has helped to increase understanding, it has potentially increased the successfulness of alpine management.

\section{Acknowledgements}

We would like to acknowledge and thank Hannah Windley and Adrienne Nicotra for their resource assistance and support. 


\section{References}

Belovsky GE, Jordan PA (1981) Sodium dynamics and adaptations of a moose population. Journal of Mammalogy 62: 613-21. doi. org/ $10.2307 / 1380408$

Best EC, Joseph J, Goldizen AW (2013) Facultative geophagy at natural licks in an Australian marsupial. Journal of Mammalogy 94:, 1237-47. doi.org/10.1644/13-MAMM-A-054.1

Blair-West JR, Coghlan JP, Denton DA, Nelson JF, Orchard E, Scoggins BA, Wright RD (1968) Physiological, morphological and behavioural adaptation to a sodium deficient environment by wild native Australian and introduced species of animals. Nature 217: 922-8. doi. org/10.1038/217922a0

Denton DA (1982) The Hunger for Salt: An Anthropological, Physiological and Medical Analysis. Springer-Verlag, New York.

Díaz S, Cabido M (1997) Plant functional types and ecosystem function in relation to global change. Journal of Vegetation Science 8: 463-74. doi.org/10.2307/3237198

Forsyth DM, Scroggie MP, Arthur AD, Lindeman M, Ramsey DSL, McPhee SR, Bloomfield T, Stuart IG (2015) Density-dependent effects of a widespread invasive herbivore on tree survival and biomass during reforestation. Ecosphere 6(4): 1-17. doi.org/10.1890/ES14-00453.1

Jensen TC, Meland S, Schartau AK, Walseng B (2014) Does road salting confound the recovery of the microcrustacean community in an acidified lake? Science of the Total Environment 478: 36-47. doi. org/10.1016/j.scitotenv.2014.01.076

Kaspari M, Chang C, Weaver J (2010) Salted roads and sodium limitation in a northern forest ant community. Ecological Entomology 35: 543-8. doi.org/10.1111/j.1365-2311.2010.01209.x

Kaspari M, Yanoviakc SP, Dudley R (2008) On the biogeography of salt limitation: A study of ant communities. Proceedings of the National Academy of Sciences of the United States of America 105: 17848-51. doi. org/10.1073/pnas.0804528105 
McGill BJ, Enquist BJ, Weiher E, Westoby M (2006) Rebuilding community ecology from functional traits. Trends in Ecology and Evolution 21: 178-85. doi.org/10.1016/j.tree.2006.02.002

Rothman, JM, Van Soest PJ, Pell AN (2006) Decaying wood is a sodium source for mountain gorillas. Biology Letters 2: 321-4. doi. org $/ 10.1098 / \mathrm{rsbl} .2006 .0480$

Weir JS (1972) Spatial distribution of elephants in an African national park in relation to environmental sodium. Oikos 23: 1-13. doi. org/10.2307/3543921 
This text is taken from Researching functional ecology in Kosciuszko

National Park, edited by Hannah Zurcher, Chia Ming-Dao, Michael Whitehead and Adrienne Nicotra, published 2017 by ANU eView, The Australian National University, Canberra, Australia. dx.doi.org/10.22459/RFEKNP.11.2017.12 